\title{
Extinction of mammalian populations in conservation units of the Brazilian Cerrado by inbreeding depression in stochastic environments
}

\author{
Marcel Müller Fernandes Pereira da Silva ${ }^{1}$ and José Alexandre Felizola Diniz-Filho ${ }^{2}$ \\ ${ }^{1}$ Programa de Pós-Graduação em Ecologia e Evolução, Instituto de Ciências Biológicas, \\ Universidade Federal de Goiás, Goiânia, GO, Brazil. \\ ${ }^{2}$ Departamento de Biologia Geral, Instituto de Ciências Biológicas, Universidade Federal de Goiás, \\ Goiânia, GO, Brazil.
}

\begin{abstract}
Despite methodological and theoretical advances in conservation genetics, data on genetic variation on broad regional spatial scales are still scarce, leading conservation planners to use general heuristic or simulation models for an integrated analysis of genetic, demographic and landscape parameters. Here, we extended previous results by evaluating spatial patterns of extinction by inbreeding depression under stochastic variation of environments for mammalian populations in 31 conservation units of the Brazilian Cerrado. We observed a large spatial variation of times to extinction, for different conservation units and body-size classes of species. For small-bodied species $(500 \mathrm{~g})$, the population times to extinction in the conservation units were usually longer than 200 years, whereas for medium-bodied $(5 \mathrm{~kg})$ and large-bodied $(50 \mathrm{~kg})$ species this time was considerably shorter, and only a few units would maintain viable populations for more than 100 years. These figures are consistent with the current status of mammalian conservation in Brazil, and hopefully the simulated scenarios can be integrated to patterns of human occupation and habitat loss in the biome, in order to furnish overall guidelines for biodiversity conservation.
\end{abstract}

Key words: population persistence, population viability analysis, mammals, Cerrado, conservation units.

Received: June 28, 2007; Accepted: January 17, 2008.

Evaluating broad-scale patterns in genetic diversity was the background for the development of "landscape genetics", a new discipline in Genetics that aims to provide information on how landscape and environmental features influence population genetic structure (Manel et al., 2003; Pearse and Crandall, 2004; Kidd and Ritchie, 2006; Storfer et al., 2006). The basic idea is to evaluate spatial patterns of genetic variation and to test for correlations between genetic discontinuities among local populations and landscape-level features, especially those related to recent human occupation (Manel et al., 2003), in order to use this knowledge for developing better conservation strategies (e.g., Diniz-Filho and Telles, 2002, 2006). Its implications on conservation are based on the assumption that habitat fragmentation, loss or conversion, generated by different types of human activities, can lead local populations to extinction, because of the decreasing levels of gene flow and reduction in effective population sizes (Fahring, 2003). On the other hand, despite methodological and theoretical ad-

Send correspondence to José Alexandre Felizola Diniz Filho. Departamento de Biologia Geral, Instituto de Ciências Biológicas, Universidade Federal de Goiás, Caixa Postal 131, 74001-970 Goiânia, GO, Brazil. E-mail: diniz@icb.ufg.br. vances provided by landscape genetics, data on genetic variation on broad regional spatial scales are still scarce, and therefore conservation planners can use overall and heuristic models which allow an integrated analysis of genetic, demographic and landscape parameters that, in turn, can provide data for an evaluation of biodiversity persistence and extinction risks (Henle et al., 2004). These models are usually parameterized by real-life history parameters of the target species or populations and by the environmental characteristics of the region in which the populations are conserved (Frankham et al., 2002; Morris and Doak, 2002; Rodrigues and Diniz-Filho, 2007).

Here, we extended previous results reported by Rodrigues and Diniz-Filho (2007) by evaluating spatial patterns of extinction in different body-size classes (hypothetical "species") of mammalian populations in conservation units of the Brazilian Cerrado. We started by assuming, under a pessimistic scenario of quick habitat loss and fragmentation in the Brazilian Cerrado (Klink and Machado 2005), that in these units isolation among local populations of hypothetical species exists. Our population dynamics simulations were based on Tanaka's (2000a) model of extinction by inbreeding depression under stochastic environ- 
ments (see also Tanaka, 1997, 1998, 2000b), as explained in detail in Rodrigues and Diniz-Filho (2007). This model is based on three dynamic recurrence equations for mean allele frequency $q$, inbreeding coefficient $F$ and population size $N$. Unless otherwise specified, all parameters used here follow previous descriptions by Rodrigues and Diniz-Filho (2007).

We applied Tanaka's (2000a) model to three sets of hypothetical mammal species, with body sizes equal to $500 \mathrm{~g}, 5000 \mathrm{~g}$ and $50000 \mathrm{~g}$, respectively. The distribution of these 'species' was such that they were found in 31 fullprotection conservation units of the Brazilian Cerrado (Figure 1), with areas ranging from 99.31 to $7,298 \mathrm{~km}^{2}$. To obtain average population densities for the three species based on their body sizes $(D)$, we used the allometric equations of Silva and Downing (1995) for all mammals, given by: $D=1.33+(-0.85 \log M)+\left(0.04 \log M^{2}\right)+\left(0.05 \log M^{3}\right)$, where $D$ is the population density in individuals $/ \mathrm{km}^{2}$ and $M$ is the body size in grams. We then multiplied this value by the total area size of each conservation unit, to obtain the expected population density for each area. This equation allowed a much more conservative (low) population size compared to the one used by Rodrigues and Diniz-Filho (2007) based on microsatellite diversity under a stepwise mutation model.

We simulated population dynamics under inbreeding depression for the three populations in each of the 31 conservation units using the following parameters: growth rates of the three species were estimated using the empirical equation of Alroy (2001), inbreeding coefficients $F=0.2$, and coefficient of variation of populations of 20 individuals. Because we were simulating population dynamics processes in a conservation unit which we assumed to remain fully preserved, we used relatively low rates of decrease in carrying capacity $K$, equal to 0.01 individuals/year. We further assumed that, although these areas were not directly affected by the problems of the surrounding environments, indirect effects would lead to reduction of the population carrying capacity, reduced anyway through border effects, such as reduction in population size by preys, pollution or loss of specific suitable habitats within the units. Other genetic load parameters were equal to those used by Tanaka (2000a), so that $\mu=10^{-6}, n=15000$ loci, and selection coefficient $s=1$.

Under the simulated scenario, it was possible to observe a great spatial variation of times to extinction, for different conservation units and species body sizes (Figure 1). Overall, the times to extinction were much shorter than those obtained previously by Rodrigues and Diniz-Filho (2007), because of the more conservative population density estimates. For small-bodied species (500 g), the populations estimated were larger and times to extinction in the conservation units were usually longer than 200 years. For medium-bodied $(5 \mathrm{~kg})$ and even more for large-bodied species $(50 \mathrm{~kg})$, this value was reduced, since only a few units
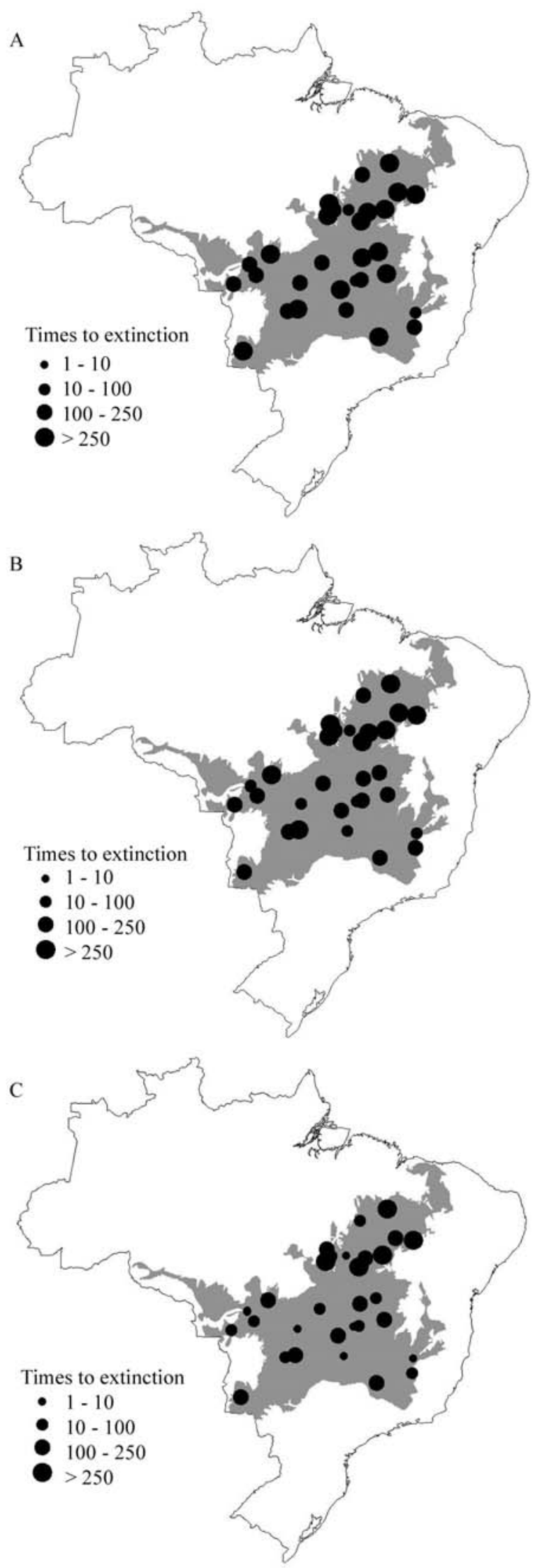

Figure 1 - Results of the simulations in 31 conservations units, showing the variation in times to extinction (years) for the different body-size classes: $500 \mathrm{~g}$ (A), $5000 \mathrm{~g}(\mathrm{~B})$, and $50000 \mathrm{~g}(\mathrm{C})$. 
would be capable of maintaining viable populations for more than 100 years. These figures are consistent with the current status of mammalian conservation in Brazil, and actually only very few conservation units are large enough to maintain viable populations of large mammals, such as tapirs (Tapirus terrestris), and especially carnivores such as jaguars (Panthera onca).

The variations in average times to extinction were logarithmically related to area for all body-size classes, and tended to stabilize for large conservation units (i.e., larger than $5000 \mathrm{~km}^{2}$ ) (Figure 2). They were also parallel, so that the nonlinear relationships between body size and all other population parameters (densities, growth rates) did not cause interactions in the spatial distribution of extinction risks as a function of area in the modeling process.

It is worth noticing that the simulated scenarios were conservative (i.e., the estimated times to extinction were probably lower than reality) with regard to spatial patterns in abundance and other life-history and ecological traits, such as diet. This was a result of the fact that the population densities were estimated using general allometric equations for mammals; more specific equations for carnivores, for example, would have produced even lower population density figures (see Silva and Downing, 1995). Moreover, it is also important to consider that, although small-bodied mammalian species would persist for much longer times than larger ones, these species usually have smaller geographic ranges, so they would not be actually found in all units (see Brown, 1995; Diniz-Filho et al., 2005). Estimates will vary on a species basis, because of variations in the "permeability" of the ecological matrix (fragmented and human-converted landscape) for different species, and their ability to maintain populations outside conservation units.

On the other hand, this reduction in persistence time with body size is a direct consequence of variations abundance and growth rates generated in allometric equations, and of course the absolute values of time to extinction depend on these parameters and equations. So, although they should be interpreted with caution, the spatial patterns of relative times can be well discussed in a regional context. We found a general north-south gradient, in which the highest persistence times are found in the northern part of the Cerrado,because of the larger size of the conservation units in that region. Although this was the only landscape-level parameter in the simulations performed here, it must have a synergistic effect with other socio-economic variables and should be interpreted together with patterns of the historical and economic occupation of the Cerrado (see Rangel et al., 2007). The process of more intense human occupation of the Cerrado that occurred over the last 50 years, especially after the foundation of Brasilia, was spatially structured and characterized by agricultural expansion fronts from South and Southeast Brazil (Klink and Moreira, 2002; Klink and Machado 2005). The consequence was that habitat loss and fragmentation were more intense in these regions, so that

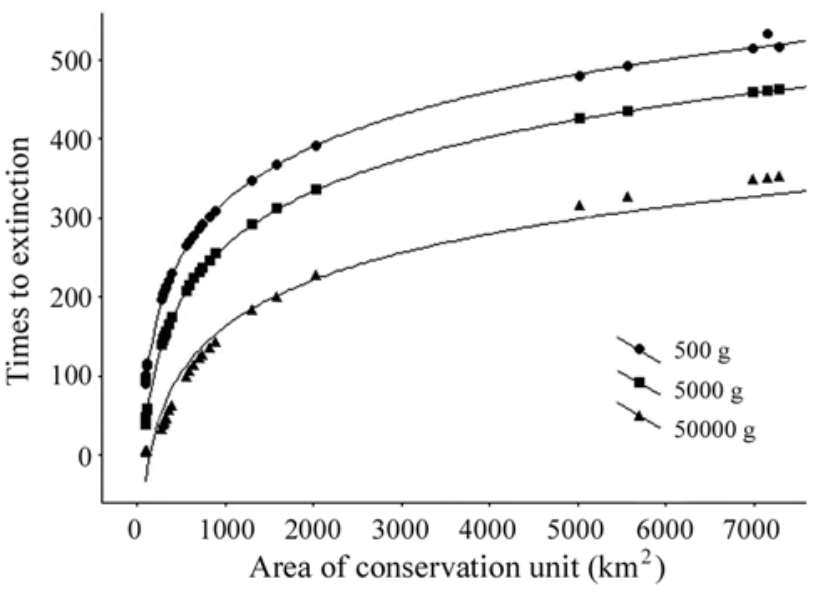

Figure 2 - Relationship between average times to extinction (years) and area of the 31 conservation units, for the three body-size classes.

larger natural areas are now mainly found in the northern part of the biome. Since in these areas the cost of land acquisition is lower and there is less agricultural occupation, the conservation units are larger there, allowing higher persistence times in the simulations performed by us. However, the small total area preserved in the full-conservation units established in the Brazilian Cerrado, when compared, for example, to the area of the other Brazilian "biodiversity hotspot", the Atlantic Forest, is a well-known problem (Myers et al., 2000; Klink and Machado 2005; Marris, 2005).

At the same time, the spatial structure found here must be reinforced by the isolation effects created by habitat loss and fragmentation. We assumed that every conservation unit is isolated from the others and that migration rates are small, which is probably close to the truth for the southern and southeastern part of the Cerrado (see Telles et al., 2007). So, the relative times simulated in the south are probably more realistic than those of the northern part of the biome, because well preserved natural habitats allow more gene flow and increase in effective population size. Thus, efficient conservation strategies can be more successfully implemented in this northern part of the biome, which is also important in view of the large amounts of preserved natural habitats and the lack of good knowledge of the biodiversity patterns (Bini et al., 2006). Furthermore, our results reinforce the need for urgent and more effective conservation actions in the south-southeastern region of the Cerrado, historically the part of the biome more densely occupied by human activities, in order to minimize the synergetic effects of isolation, habitat loss and reduced conservation area.

\section{Acknowledgments}

We thank Bruno Barreto and Guilherme Oliveira for their help with maps and for providing allometric equations, and the two anonymous reviewers for suggestions 
that improved the manuscript. This work was partially supported by a PRONEX program (CNPq/SECTE-GO) for establishing conservation priorities in the Brazilian Cerrado.

\section{References}

Alroy J (2001) A multi-species overkill simulation of the endPleistocene megafaunal mass extinction. Science 292:1893-1896.

Brown JH (1995) Macroecology. University of Chicago Press, Chicago, 269 pp.

Bini LM, Diniz-Filho JAF, Rangel TFLVB, Bastos RP and Pinto MP (2006) Challenging Wallacean and Linnean shortfalls: Knowledge gradients and conservation planning in a biodiversity hotspot. Divers Distrib 12:475-482.

Diniz-Filho JAF and Telles MPC (2002) Spatial autocorrelation analysis and the identification of operational units for conservation in continuous populations. Conserv Biol 16:924935.

Diniz-Filho JAF and Telles MPC (2006) Optimization procedures for establishing reserve networks for biodiversity conservation taking into account population genetic structure. Genet Mol Biol 29:207-214.

Diniz-Filho JAF, Carvalho P, Bini LM and Tôrres NM (2005) Macroecology, geographic range size-body relationship and minimum viable population analysis for New World Carnivora. Acta Oecologica 27:25-30.

Fahring L (2003). Effects of fragmentation on biodiversity. Annu Rev Ecol Syst 34:487-515.

Frankham R, Ballou JD and Briscoe DA (2002) Introduction to Conservation Genetics. Cambridge University Press, Cambridge, $640 \mathrm{pp}$.

Henle K, Lindemayer DB, Margules CR, Saunders DA and Wissel C (2004) Species survival in fragmented landscapes: Where are we now? Biodiv Conserv 13:1-8.

Kidd DM and Ritchie MG (2006) Phylogeographic information systems: Putting the geography into phylogeography. J Biogeogr 33:1851-1865.

Klink CA and Machado RB (2005) Conservation of the Brazilian cerrado. Conserv Biol 19:707-713.

Klink CA and Moreira AG (2002) Past and current human occupation, and land use. In: Oliveira PS and Marques RJ (eds) The Cerrado of Brazil: Ecology and Natural History of a Neotropical Savanna. Columbia University Press, New York, pp 69-88.
Manel S, Schwartz MK, Luikart G and Taberlet P (2003) Landscape genetics: Combining landscape ecology and population genetics. Trends Ecol Evol 18:89-197.

Marris E (2005) The forgotten ecosystem. Nature 437:944-945.

Morris WF and Doak DF (2002) Quantitative Conservation Biology: The Theory and Practice of Population Viability Analysis. Sinauer Associates, Sunderland, 480 pp.

Myers N, Mittermeier RA, Mittermeier CG, da Fonseca GAB and Kent J (2000) Biodiversity hotspots for conservation priorities. Nature 403:853-858.

Pearse DE and Crandall KA (2004) Beyond $\mathrm{F}_{\mathrm{ST}}$ : Analysis of population genetic data for conservation. Conserv Genet 5:585602.

Rangel TFLVB, Bini LM, Diniz-Filho JAF, Pinto MP, Carvalho P and Bastos RP (2007) Human development and biodiversity conservation in Brazilian Cerrado. Appl Geogr 27:14-27.

Rodrigues FM and Diniz-Filho JAF (2007) Extinction of canid populations by inbreeding depression under stochastic environments in Southwestern Goias State: A simulation study. Genet Mol Biol 30:121-126.

Silva M and Downing JA (1995) The allometric scaling of density and body mass: A nonlinear relationship for terrestrial mammals. Am Nat 145:704-727.

Storfer A, Murphy MA, Evans JS, Goldberg CS, Robinson S, Spear SF, Dezzani R, Delmelle E, Vierling L and Waits LP (2006) Putting the 'landscape' into landscape genetics. Heredity $98: 128-142$.

Tanaka Y (1997) Extinction of populations due to inbreeding depression with demographic disturbances. Res Pop Ecol 39:57-66.

Tanaka Y (1998) Theoretical aspects of extinction by inbreeding depression. Res Pop Ecol 40:279-286.

Tanaka Y (2000a) Theoretical properties of extinction by inbreeding depression under stochastic environments. In: Ferson $\mathrm{S}$ and Burgman M (eds) Quantitative Methods for Conservation Biology. Springer-Verlag, New York, pp 274-290.

Tanaka Y (2000b) Extinction of populations by inbreeding depression under stochastic environments. Res Pop Ecol 42:55-62.

Telles MPC, Diniz JAF, Bastos RP, Soares TN, Guimarães LD and Lima LP (2007) Landscape genetics of Physalaemus cuvieri in Brazilian Cerrado: Correspondence between population structure and patterns of human occupation and habitat loss. Biol Conserv 139:37-46.

Associate Editor: João S. Morgante

License information: This is an open-access article distributed under the terms of the Creative Commons Attribution License, which permits unrestricted use, distribution, and reproduction in any medium, provided the original work is properly cited. 